Note: This is a pre-copy-editing, author-produced PDF of an article accepted for publication in British Journal of Social Psychology following peer review. The definitive publisher-authenticated version [Morgan M and Grube JW (1991) Closeness and peer group influence, British Journal of Social Psychology, 30, 159-169] is available online at http://bpsoc.publisher.ingentaconnect.com/content/bpsoc/bjsp

\title{
Closeness and peer group influence
}

\author{
Mark Morgan* \\ St Patrick's College, Dublin 9, Ireland \\ Joel W. Grube \\ Prevention Research Center, Berkeley, CA \\ Published in British Journal of Social Psychology (1991), 30, 159-169 \\ Copyright: The British Psychological Society
}

\begin{abstract}
This study hypothesized that closeness of peer group relationships would be a critical factor in determining peer influence on substance use. The hypothesis was examined in a panel study of the effects of peer approval and behaviour on cigarette smoking, drinking and other drug use among Irish adolescents. In support of the closeness hypothesis, the influences relating to peers identified by respondents as 'friends' were better predictors of drug use than were the corresponding factors relating to same-aged peers, while the person identified as the 'best friend" seemed uniquely influential. Furthermore, there were important differences associated with maintenance of drug use as opposed to initiation, both as regards the type of friends and the mediating factors that were important. In particular, it emerged that several good friends were influential (by means of example and approval) in initiation, while the best friend had a critical role in the maintenance of drug use.
\end{abstract}

In the existing literature on substance use, 'peer group pressure' is frequently thought to be an important factor influencing cigarette smoking, alcohol and other drug use.

Whether measured by means of perceived norms or through an independent measure of use/approval by the peer group, the association is robust and consistent (Kandel, 1980). However, while the relationship between drug use and peer influences has been found in numerous studies (e.g. Chassin, Presson, Sherman, Corty \& Olshavsky, 1984; Kaplan, Martin \& Robbins, 1984), there is considerable conceptual confusion arising from a failure to make differentiations between the various reference groups who may constitute the peer group. The various items used to define 'peer group' include the following: 'other pupils in your school' (Johnson, Bewley, Banks, Bland \& Clyde, 1985), 'other teenagers whose opinion you value' (Akers, Krohn, Lanza-Kaduce \& Radosevich, 1979), 'current friends and acquaintances'(Ritter, 1988), 'sociometric groups or cliques' (Cohen, 1977), 'your five closest friends' (Chassin, Presson, Sherman, Montello \& McGrew, 1986) and 'your best friend" (Kandel, 1985). 
While the studies listed above have demonstrated peer group influences of varying magnitudes, the work has lacked a rationale relating to how peers should be identified and which predictions might be made on the relative influence of one group of agemates as opposed to another. It is the central hypothesis of the present article that social influence varies with the closeness of peer relationships. In turn, the results may help to clarify some of the conceptual confusion surrounding the construct of 'peer pressure' in the drug use literature.

Therefore, a first objective of the present study was to determine the extent to which perceptions relating to (i) the person identified by respondents as their 'best friend", (ii) other "good friends' and (iii) 'young people my age' are important influences in adolescent use of cigarettes, alcohol and other drugs. On the basis of the findings relating to closeness, it was predicted that perceptions of best friends would be more highly related to adolescent substance use than perceptions of other good friends, which, in turn, would be more closely related with reported use than influences associated with 'people my age'.

\section{Mediation of peer influences}

A second major question concerns how the impact of peers is mediated. Two aspects of influence have been extensively examined, namely, perceived drug use and perceived approval of drug use. Perceived drug use by peers may bring about the modelling of this behaviour either through direct imitation or through disinhibition (Bandura, 1986).

Perceived approval consists of the beliefs about peer approval or disapproval of drug use and is generally regarded as operating by means of social reinforcement (Kandel, 1985). While these peer group influences have been examined in studies of adolescent drinking (Bank, Biddle, Anderson, Hauge \& Keats, 1985; Biddle, Bank \& Marlin, 1980) and in studies of drug use (Kandel, 1985), the present data set affords the opportunity to give a comprehensive picture of the relative importance of example and approval in the context of smoking, drinking, as well as illicit drug use.

\section{Initiation vs. maintenance of drug use}

There is ample evidence in the literature that the factors associated with initiation to drug use may be somewhat different from those associated with the maintenance of an established pattern of drug use (Chassin et al., 1986; Kandel, 1985). For example, the work of Kandel (1985) has demonstrated that the importance of the best friend compared with parents varies at different stages of drug use (different substances and in relation to acquisition vs. maintenance). The present study, which features a longitudinal design allows for the separation of these stages. A particular focus was on the extent to which the influence of the best friend as opposed to other friends was different during acquisition and maintenance phases.

\section{Developmental factors}

There is conflicting evidence on developmental changes in the size of peer influences during adolescence. A study by Morgan $6 c$ Grube (1989) showed that the relative importance of beliefs about consequences vs. social influences (including peer factors) changed dramatically during the adolescent years. On the other hand, Eiser, Morgan, Gammage \& Gray (1989) found no evidence of changes in the importance of subjective norms from ages 10 to 16 years. However, both of these studies were cross-sectional in design. A longitudinal study that also examines developmental factors would seem to be particularly valuable in this context. Therefore, the present study focused on the relative influences of same-aged peers vs. best friend vs. other friend, from ages 13 to 17 years. 
A panel study is described below in which reports from Irish adolescents on various aspects of peer influences at Time I were used to predict their reported use of cigarettes, alcohol and illegal drugs one year later (Time 2). The distinction into initiation and maintenance influences was addressed through further separate analyses for those respondents who indicated that they were (or were not) current users of a particular substance at Time 1.

\section{Method}

\section{Survey design}

A sample of Dublin post-primary pupils anonymously completed questionnaires in February 1984, in March/April 1984 and again in March/April 1983. The questionnaires asked about a range of variables relating to drug use. Files were matched across che three phases by means of a self-generated code (Grube, Morgan \& Kearney, 1989; Kearney, Hopkins, Mauss \& Weisheit, 1984). For the present analyses, the first two phases are treated as 'Time 1', since the focus of these testing sessions was on establishing reliability of the measures rather than on factors associated with change.

\section{Sample}

The sampling frame was the official Department of Education list of post-primary schools in the greater Dublin area. The sampling unit consisted of classes within schools. For each post-primary class level a sample of schools was obtained, stratified for gender, size and type of school. All but two of the 24 schools selected agreed to participate and the two non-cooperating schools were replaced from the original sampling list by other schools matched on the selection characteristics. At Time 1, data were obtained from 2927 and 2782 students, respectively, at the two testing sessions, while at Time 2 data were obtained from 2057 students. The smaller size of the sample at Time 2 is due mainly to the number of students who had either completed their education or left school for other reasons. The great majority of the students were between 13 and 18 years old and the median age was 15.8 years. The sample was nearly equally divided between males and females.

The potential biasing effects of attrition were examined by comparing the respondents who attended the first phase of the study but who were not present at Time 2 . In terms of substance use behaviours, respondents lost to the study were more likely to report at Time 1 that they had smoked cigarettes, drunk alcohol or used other drugs, than were respondents who were present at both times. However, the difference is relatively modest, with retention status accounting for about 3 per cent of the variance in substance use behaviours. More importantly, it appears that the processes underlying substance use behaviours were very similar among respondents retained and lost from the study. A series of hierarchical regressions predicting Time / substance use from the major variables of theoretical interest indicated that in no case was there a substantively significant interaction between attrition status and the predictors. Thus, it seems reasonable co argue that the results regarding the prediction of Time 2 drug use were relatively unbiased by attrition.

\section{Survey instruments}

The survey instruments consisted of self-administered, structured questionnaires, with the respondents being asked to circle the appropriate answer or number for each question. Written instructions within each questionnaire assured the respondents of complete anonymity and confidentiality. 
Respondents were asked if they had ever smoked a cigarette, ever drank alcohol or ever used any of a list of 12 illicit substances. Other questions inquired how many cigarettes, on average, they had smoked daily during the past munch (on a scale of 1-20 cigarettes a day), how many times during the previous month they consumed alcohol (0-10 times) and how many times during the previous month they had used illicit drugs (0-10 times). These questions on current usage were posed in all sessions.

At Time 1 students were also asked about the drug use of their best friend, with the questions in a similar format to chose pertaining to their own drug use. Specifically, they were asked about the current smoking of their best friend', as well as their best friend's current drinking and illicit drug use. A parallel series of questions inquired about substance use by the respondents' other good friends, while a similar item required them to indicate the level of current usage by 'most young people of my age'.

For each substance, a series of questions inquired how 'your best friend' would approve of the respondent's use of the substance (five-point scale from 'disapprove extremely' co 'would not disapprove'). They were also asked about the level of approval of their other good friends on a similar scale.

A further series of items related to background factors including date of birth, gender, and mother's and father's occupations. Finally, three items were included solely as part of a self-generated identification code that was used to link each student's questionnaires over the phases: number of older brothers, number of older sisters and first letter of mother's first name.

The questionnaires were completed in the students' regular classroom, with teachers generally not being present. There were two minor deviations from this procedure. In one school a number of classes were brought together for the session while in another the class-teachers were actually in the classrooms (because of anticipated disciplinary problems), but had only minimal involvement with respondents during the testing sessions.

\section{Matching procedure}

Since questionnaires were completed anonymously, the matching of files across the testing sessions was accomplished by means of a self-generated code and an 'off-one' matching procedure (Grube et al., 1989; Kearney et al., 1984). There were seven elements to this code; gender, day, month and year of birth, number of older brothers, number of older sisters and first initial of mother's first name. These elements were used to link the questionnaires from within each school and class level. Overall, 1593 (77.3 per cent) of the questionnaires at Time 2 were matched with questionnaires from Time 1. Thus, over three-quarters of the possible matches were obtained. Given normal absences from school (about 8-10 per cent on average, and transfers of pupils together schools and classes at the end of the school year (estimated at 12-15 percent), the rate of matching is extremely satisfactory.

The possibility of bias due to the matching procedure was investigated by comparing matched and unmatched respondents on substance use variables. In fact, the unmatched respondents tended to report higher lifetime and current prevalence than did matched respondents. However, the rates differed by less than 2 per cent for each behaviour. Furthermore, previously reported analyses (Grube et al., 1989) indicated that 
the major predictors of substance use did not differ significantly among matched and unmatched subjects. Thus, the regression analyses reported below should be unbiased by the use of the matching procedure.

\section{Results \\ Reliability and validity of substance use measures}

Internal reliability coefficients were calculated for related items measuring substance use behaviours, for each testing session. These alpha coefficients ranged from .98 to .70, with a median of .81 . The test-retest reliability coefficients across the two testing sessions at Time 1 were .83, 72 and .59 for cigarette smoking, drinking and illicit drug use, respectively. The different levels of test-retest reliability may be due to the fact that some substance use behaviours are inherently less stable than others. Two factors may account for this instability. The first factor is the actual number of substances involved under the umbrella of drinking (beer, spirits, etc.) and in illicit drug use (solvents, marijuana), in contrast to cigarette smoking. A second factor may be access. In general, these young people have greater access to cigarettes than to alcohol, while in turn illicit drugs would be even more difficult to obtain (Grube, Morgan \& McGree, 1986). Since ease of access to a substance will influence the stability of behaviour, those substances that are easily obtained will have higher test-retest reliability coefficients.

The anonymity and confidentiality procedures implemented during the survey administration were designed to reduce under-reporting as much as possible, while the extent of over-reporting was investigated by including a fictitious drug in the list of substances that comprised the illicit drug use measures. Overall, 1.8 per cent of the respondents reported that they had, at some time, used the fictitious substance and 1.1 per cent reported that they had used it within the past month. Data from these subjects were not included in the subsequent analyses.

\section{Prediction of drug use and peer/friend influences}

Table 1 shows commonality analyses (Pedhazur,1982) of factors relating to peer influence with Time 2 current use as the dependent variable. These analyses involved (i) predicting substance use without control on other domains, i.e. zero order correlations, and (ii) calculating the increment in prediction for each influence, while controlling for other influences, i.e. the 'unique contribution' of each predictor.

Several features of these results are striking. First, the relationship between usage by friends (both best friends and other good friends) and reported drug use is much stronger than that with the perceived use by other same-aged peers. In turn, best friend use is more strongly related to reported use than is use by other good friends. In fact, best friend use remains a strong and significant predictor after controlling for other friends' use and peer use. In contrast, other friends' use diminishes considerably in importance and same-aged peers' use is not statistically significant, after applying a similar control.

A second feature is that perceived use is a much stronger predictor of substance use than perceived approval, both for best friends and for other good friends. In fact, other friends' approval at Time 1 does not add significantly to the prediction of either Time 2 cigarette smoking, alcohol consumption or other drug use. Thirdly, there is a remarkable pattern of similarity in the results for all substances. In each case, the more intimate the group, the more successful the prediction. 
Table I. Prediction of substance use from friend/peer example and approval: A commonality analysis

\begin{tabular}{|c|c|c|c|c|}
\hline \multirow[b]{2}{*}{ Influence } & \multicolumn{2}{|c|}{$\begin{array}{l}\text { Each reference group without } \\
\text { control for other reference groups }\end{array}$} & \multicolumn{2}{|c|}{$\begin{array}{l}\text { Each reference group controlling } \\
\text { for other reference groups }\end{array}$} \\
\hline & $R^{2}$ & $\mathrm{~F}$ & $R^{2}$ & $\mathrm{~F}$ \\
\hline \multicolumn{5}{|c|}{ Cigarette smoking $(N=1568)$} \\
\hline Best friend use & .22 & $978.45^{\star *}$ & .08 & $147.56^{\star *}$ \\
\hline Other good friends' use & .15 & $765.32^{* *}$ & .02 & $38.89^{\star \star}$ \\
\hline Same-aged peers' use & .03 & $20.72^{\star *}$ & .00 & 1.33 \\
\hline Best friend approval & .08 & $127.98^{\star *}$ & .03 & $44.88^{\star *}$ \\
\hline Other friends' approval & .05 & $87.65^{\star *}$ & .00 & 0.98 \\
\hline \multicolumn{5}{|c|}{ Alcohol consumption $(N=1559)$} \\
\hline Best friend use & .21 & $639.14^{* *}$ & .11 & $267.10^{\star *}$ \\
\hline Other good friends' use & .16 & $542.57^{* *}$ & .02 & $39.04^{* *}$ \\
\hline Same-aged peers' use & .01 & $29.35^{\star *}$ & .00 & 0.03 \\
\hline Best friend approval & .11 & $325.76^{\star *}$ & .02 & $12.47^{\star *}$ \\
\hline Other friends' approval & .08 & $197.29^{\star *}$ & .00 & 0.76 \\
\hline \multicolumn{5}{|l|}{ Illicit drug use $(N=1542)$} \\
\hline Best friend use & .08 & $433.82^{\star *}$ & .04 & $47.20^{\star \star}$ \\
\hline Other good friends' use & .04 & $52.88^{* *}$ & .00 & 2.66 \\
\hline Same-aged peers' use & .01 & $19.14^{\star \star}$ & .00 & 1.19 \\
\hline Best friend approval & .06 & $219.83^{\star *}$ & .02 & $9.93^{\star *}$ \\
\hline Other friends' approval & .04 & $134.67^{* *}$ & .00 & 0.97 \\
\hline
\end{tabular}

Table 2. Zero order correlations of peer/friend influences and initiation vs. maintenance of drug use

\begin{tabular}{|c|c|c|c|}
\hline Influence & Cigarettes & Alcohol & Illicit drug use \\
\hline Initiation & $(\mathrm{N}=965)$ & $(\mathrm{N}=780)$ & $(\mathrm{N}=1321)$ \\
\hline Best friend use & $.18^{\star *}$ & $.21^{* *}$ & .05 \\
\hline Other good friends' use & $.12^{\star \star}$ & $.26^{\star \star}$ & .17 \\
\hline Same-aged peers' use & .02 & $.11^{* *}$ & .08 \\
\hline Best friend approval & $.17^{\star \star}$ & $.15^{\star \star}$ & $.13^{\star \star}$ \\
\hline Other friends' approval & $.13^{\star *}$ & $.17^{\star *}$ & $.14^{* *}$ \\
\hline Maintenance & $(\mathrm{N}=603)$ & $(\mathrm{N}=780)$ & $(\mathrm{N}=221)$ \\
\hline Best friend use & $.38^{* *}$ & $.35^{\star \star}$ & $.27^{\star \star}$ \\
\hline Other good friends' use & $.33^{\star \star}$ & $.30^{\star \star}$ & $.17^{\star \star}$ \\
\hline Same-aged peers' use & $.21^{* *}$ & .03 & .07 \\
\hline Best friend approval & $.18^{\star \star}$ & $.22^{\star \star}$ & $.13^{\star \star}$ \\
\hline Other friends1 approval & $.15^{\star *}$ & $.17^{\star \star}$ & $.10^{\star \star}$ \\
\hline
\end{tabular}
$\cdot p<.05 ;{ }^{* *} p<.001$. 
Table 3- Regression analyses for initiation to and maintenance of substance use Initiation Maintenance

\begin{tabular}{|c|c|c|c|c|c|c|c|c|}
\hline \multirow[b]{2}{*}{ Variable } & \multirow[b]{2}{*}{$\mathrm{b}$} & \multicolumn{3}{|c|}{ Initiation } & \multicolumn{4}{|c|}{ Maintenance } \\
\hline & & SE b & Beta & $T$ & $\mathrm{~b}$ & SE b & Beta & $T$ \\
\hline \multicolumn{9}{|l|}{ Cigarette smoking } \\
\hline Best friend smoking & .11 & .05 & .11 & $2.49^{*}$ & .47 & .10 & .27 & $4.71^{\star \star}$ \\
\hline Other friends' smoking & .02 & .05 & .02 & .87 & .24 & .09 & .15 & $2.65^{\star}$ \\
\hline Same-aged peer smoking & .04 & .04 & .03 & .90 & .06 & .11 & .03 & .56 \\
\hline Best friend approval & .19 & .05 & .12 & $3.68^{* *}$ & .12 & .14 & .05 & .89 \\
\hline Other friends' approval & .04 & .05 & .03 & .64 & .06 & .17 & .02 & .37 \\
\hline Alcohol consumption & \multicolumn{3}{|c|}{ Multiple $R=.21, R^{2}=.04$} & & \multicolumn{4}{|c|}{ Multiple $R=. .41, R^{2}=.17$} \\
\hline Best friend drinking & .09 & .05 & .08 & 1.91 & .42 & .09 & .23 & $4.45^{* \star}$ \\
\hline Other friends' drinking & .19 & .04 & .21 & $4.52^{\star \star}$ & .33 & .10 & .17 & $3.17^{\star}$ \\
\hline Same-aged peer drinking & .01 & .03 & .00 & .18 & .14 & .09 & .10 & 1.47 \\
\hline Best friend approval & .03 & .02 & .07 & 1.37 & .15 & .08 & .08 & 2.13 \\
\hline Other friends' approval & .02 & .02 & .07 & 1.42 & .18 & .13 & .09 & 1.47 \\
\hline Illicit drug use & \multicolumn{4}{|c|}{ Multiple $R=.28 . R^{2}=.08$} & \multicolumn{4}{|c|}{ Multiple $R=. .40, R^{2}=.16$} \\
\hline Best friend use & .01 & .05 & .01 & .15 & .26 & .13 & .26 & $2.06^{*}$ \\
\hline Other friends' use & .02 & .03 & .02 & .57 & .14 & .15 & .13 & .78 \\
\hline Same-aged peer use & .03 & .02 & .06 & 1.36 & .13 & .08 & .17 & 1.68 \\
\hline Best friend approval & .03 & .03 & .04 & 1.38 & .16 & .12 & .18 & 1.27 \\
\hline \multirow[t]{2}{*}{ Other friends' approval } & .02 & .01 & .06 & 1.98 & .02 & .13 & .02 & .17 \\
\hline & \multicolumn{4}{|c|}{ Multiple $R=.16, R^{2}=.03$} & \multicolumn{4}{|c|}{ Multiple $R=. .35, \quad R^{2}=.12$} \\
\hline
\end{tabular}
${ }^{*} p<05 ;{ }^{* *} p<001$.

\section{Initiation to drug use}

The previous analyses are based on all respondents and have therefore included young people who were already regular users of the various drugs at Time I, as well as those who had become regular users in the year between Time 1 and Time 2 . To focus on factors specifically associated with initiation, a series of further analyses involved only those subjects who at Time 1, were not current users during the previous month. Table 2 shows the correlations between Time 1 peer factors and current substance use for these respondents, while Table 3 displays the results of the regression analyses (all variables entered together). To examine the extent to which the relationships between influences and use may have been moderated by age, a series of product vectors (between age and the predictors) were entered in the regression equation and the increment in prediction examined. For neither smoking, drinking nor illicit drug use was there a substantively significant increment beyond that of the initial predictors $(/ \wedge$-squared increment was less than I per cent in all cases).

\section{Maintenance/cessation of drug use}

To examine factors that were particularly related to maintenance of substance use, a series of analyses parallel to those for initiation were carried out, involving those respondents who reported at Time 1 that they had used the substance in question during the previous month. The resulting correlations and regression coefficients are shown in Tables 2 and 3, respectively. An examination of the influence $X$ age interaction revealed no significant increase in the prediction of Time 2 usage. 
A comparison of the results for initiation and maintenance reveals that, in comparison with the prediction for all respondents, the correlations are considerably attenuated. This is largely because the analyses for initiation and maintenance are confined to two groups who are relatively homogeneous with respect to the predicted behaviour at Time I, while the prediction analyses included the full range of behaviours. However, it is apparent that the pattern of influences is different for each phase. Specifically, in the case of maintenance the strongest predictor is use of a substance by a respondent's best friend. This holds true for smoking, drinking and illicit drug use. In contrast, in the case of initiation, no single influence is so strong; indeed, the best friend and other friend influences were very similar to each other. A final point of contrast is that, for the initiation phase, friends' approval seems to be as important as friends' use. Overall, therefore, the factors predicting initiation to a substance are less differentiated than the factors predicting maintenance/cessation both in terms of the closeness of peer relationships and in terms of mediating processes.

\section{Discussion}

The primary purpose of this study was to examine the extent to which closeness of peer group relationships was a significant factor in peer influence. The specific focus was on the different roles of 'best friend', 'good friends' and 'same-aged peers' in the establishment, maintenance and prediction of drug use. A second major purpose was to establish the way in which peer/friend influences are mediated, particularly the extent to which use of a substance by peers may be important in comparison with approval of such use.

On the basis of a simple prediction of use from peer factors measured one year earlier, closeness of the peer group is indeed a significant dimension of peer influence. Specifically, friend influences were shown to be more important than were same-aged peer influences, and best friend influences were more important than the impact of other good friends. In turn, the behaviour (use of a substance) of friends was a more potent predictor of later use than was the extent to which these same friends approved of substance use. A particularly striking feature of the results was the extent to which best friend use of a substance uniquely' predicted later smoking, drinking and illicit drug use. In other words, there were large increments in the level of prediction even with all other kinds of peer influences controlled. These results demonstrate in a striking way that proximal peer group factors are powerful predictors of substance use.

However, these analyses were concerned solely with prediction and included all respondents, i.e. those who already were users at Time I as well as those who were not. Thus, the strength of the associations between peer and friend influences and use may reflect one of two processes: (i) peer/friend influences at Time I may have resulted in subsequent usage, or (ii) the friends identified at Time 1 may have been selected as a result of previous usage rather than causing subsequent use. In other words, it is likely that there is a confounding of factors associated with initiation and those relevant to maintenance/cessation. These problems have frequently been raised in criticisms of cross-sectional studies, on the grounds that such studies do not easily allow a separation of such influences (Chassin et a/., 1986).

The separate analyses for those subjects who were (or were not) current users at Time 1 is, therefore, aimed at disentangling such processes, by creating homogeneous groups with regard to the substance in question. While this resulted in a considerable attenuation in the size of the correlation and regression coefficients, the problems of 
interpretation are considerably eased. In fact, the results showed a rather different pattern of relationship for each phase. As regards maintenance of substance use, there are several similarities to the prediction study that included all respondents. The closeness of the peer group seems to be a critically important dimension. Friends' influence predicted maintenance better than same-aged peers, and best friend influences are stronger than the influence of other good friends. Furthermore, perceived use of a substance by friends is more strongly related to reported use than is perceived approval. This pattern obtains for smoking, drinking and for illicit drug use. On the other hand, the factors that predict initiation are much less differentiated. Here it emerges that best friend influences and those of other good friends are about equally strong predictors of initiation. Furthermore, the mediating influences of example and approval seemed to be at the same level. In contrast to the findings in relation to maintenance, there was no suggestion that use by best friend was singularly important. On the other hand, it was evident that the influence of same-aged peers was minimal both for initiation and for maintenance.

While the literature on drug use has not to date focused on the significance of closeness of peer relations, the research on friendship is consistent with the results emerging here. Thus, it has been shown that the interactions of friends and non-friends differ in terms of positive exchanges and mutuality (Newcomb, Brady \& Hartup, 1979), conflict resolution (Hartup, Laursen, Stewart \& Eastenson, 1988), exchange dynamics (Hays, 1989), and in terms of domains of interpersonal competence (Buhrmester, Furnam, Wittenberg \& Ries, 1988). The necessity for this kind of differentiation is also shown in studies on children's conceptions of acquaintances and friends. The developmental evidence suggests that children acquire a differentiated and hierarchically organized conceptual system with which they construe their interpersonal relationships (Foot, Chapman \& Smith, 1980; Huston \& Levinger, 1978). Friendships are perceived by children to be markedly different from other kinds of social relations in as much as friendships are reciprocal in nature and involve closeness and emotional support (Hays, 1984, 1985).

There are suggestions in the literature that peers of varying degrees of closeness may play different roles in social development. For example, in the peer acceptance literature, it has been shown that there is an important distinction to be made between the influences of 'classmates' or 'peers' and the relatively small number of age-mates that make up an adolescent's 'friends' (Parker \& Asher, 1987). Also, the domains of behaviour that may be influenced by 'peers' and 'friends' may be very different (McGuire \& Weisz, 1982).

\section{Age and substances factors}

The failure to find significant moderating effects for age suggests that the influencing processes are relatively constant across the adolescent years from ages 13 to 17 . The previous work in this area has produced mixed results. In the context of cigarette smoking, studies by Krosnick \& Judd (1982) and by Morgan \& Grube (1989) showed significant changes in peer influences during adolescence, while Chassin et al. (1986) found that the magnitude of peer influence did not vary across the 6th to I lth grade levels. The interpretation proposed by Chassin etal. is that interactions are more likely to emerge in cross-sectional studies because of the heterogeneous nature of a crosssectional sample (mix of long-standing substance users and non-users at each age level), while a panel study allows for the identification of homogeneous groups. The fact that the present panel study failed to show any moderating effects of age for either 
initiation or maintenance of smoking, alcohol use or illicit drug use supports the Chassin et al. interpretation of these seemingly conflicting findings.

The fact that the outcomes for smoking, drinking and other drug use showed a similar pattern seems initially to be contradicted by the findings of Kandel (1985), who round that, in many respects, the influence of peers was different not only in acquisition compared with continuance phases (as found in the present study) but also depended somewhat on the particular substance in question. However, it is worth noting that the range and classification of drugs was different from that used here. For example, because of the relatively low rates of illicit drug use in our sample, the category 'other drug use", while comprising largely solvent use and marijuana use, also includes a range of other illegal substances. Similarly, alcohol consumption includes mainly beer, but also includes spirits and cider. Whether the different outcomes are due to differences in classification, methodology, cultural differences or to some combination of these, must remain a matter for conjecture.

\section{Implications for prevention}

The present results may have important implications for programmes that attempt to prevent substance use among schoolchildren. The evidence on the effectiveness of programmes that attempt to prevent cigarette smoking are especially relevant, since such programmes have undergone extensive and long-term evaluation. These evaluations have shown that, while a focus on long-term consequences of smoking is relatively ineffective, a focus on specific skills to resist social pressures to begin smoking is more promising, especially if same-aged peer leaders act as teachers for the programme (Best, Thomson, Santi, Smith \& Brown, 1988).

These results suggest ways in which such programmes may be made more effective both in terms of content and of delivery. As regards the focus of such programmes, the above evidence suggests that the necessary social skills should not be concerned with remote anonymous peers, but rather with friends. It also seems that the kinds of intervention that may be most effective will be different for acquisition vs. maintenance stages. Finally, the use of assigned peer leaders might not necessarily be the most effective way of delivering such programmes. The use of sociometric techniques might result in the use of leaders who are 'closer' and who may be more influential through exhortation and example.

\section{Limitations}

It could be argued that, since the reports on friends' use and approval of use come from the respondents there might well be an element of rationalization and misperception by respondents resulting from the attempt to justify their behaviour by reference to the behaviours and attitudes of others. A related issue is the possibility of diminishing accuracy of less close peers, i.e. estimates of the wider peer group are likely to be relatively more neutral than estimates of close friends. In response to this criticism, two considerations are relevant. Firstly, the evidence suggests that although not perfectly correlated there is good correspondence between social influences and perceptions (Kandel, 1980, 1985; Newcomb, Huba \& Bentler, 1983). Furthermore, how others are perceived seems to be more directly important than their actual attitudes in determining substance use (Newcomb et a/., 1983). Secondly, the most interesting feature of the present results is the contrasting pattern of the acquisition and maintenance phases. Whether these changes reflect actual changes in friendship patterns, or an equally 
interesting change in perceptions consequent on usage, is a matter for further investigation.

\section{Acknowledgements}

Thanks are due to Willard W. Hartup for comments on an earlier draft and to Michael Martin for his statistical advice. This research was supported by the Educational Research Centre, St Patrick's College, by the Economic and Social Research Institute and by a grant from the Commission of the European Community to the Economic and Social Research Institute.

\section{References}

Akers, R. L., Krohn, M. D., Lanza-Kaduce, L. \& Radosevich, M. (1979). Social learning and deviant behavior: A specific test of a general theory. American Sociological Review, 44, 636-655.

Bandura, A. (1986). Social Foundations of Thought and Action. Englewood Cliffs, NJ: Prentice-Hall.

Bank, B., Biddlc, B. J., Anderson, D. S., Hauge, R., Keats, D. M., Keats, J. A., Marlin, M. M. \& Valantin, S. (1985). Comparative research on the social determinants of adolescent drinking. Social Psychology Quarterly, 48, 164-177.

Best, J. A., Thomson, S. J., Santi, S. M., Smith, E. A. \& Brown, K. S. (1988). Preventing cigarette smoking among children. Annual Review of Public Health, 9, 161-201.

Biddle, B. J., Bank, B. \&c Marlin, M. M. (1980). Social determinants of adolescent drinking: What they think, what they do and what I think and do. Journal of Studies on Alcohol, 41, 215-241.

Buhrmester, D., Furnam, W., Wittenberg, M. T. \& Reis, H. T. (1988) Five domains of interpersonal competence in peer relationships. Journal of Personality and Social Psychology, 55, 991-1008.

Chassin, L., Presson, C. C, Sherman, S. J ., Corty, E. ScOlshavsky, R. W. (1984). Predicting the onset of cigarette smoking in adolescents: A longitudinal study. Journal ofApplied Social Psychology, 14, 224-243.

Chassin, L., Presson, C. C, Sherman, S. J ., Montello, D. 8c McGrew, J. (1986). Changes in peer and parent influence during adolescence: Longitudinal versus cross-sectional perspectives on smoking initiation. Developmental Psychology, 22, 327-334.

Cohen, J. S. (1977). Sources of peer group homogeneity. Sociology of Education, 50, 227-254.

Eiser, J. R., Morgan, M., Gammage, P. 8c Gray, E. (1989). Adolescent smoking: Attitudes, norms and parental influence. British Journal of Social Psychology, 28, 193-202.

Foot, H. C, Chapman, A. J. \& Smith, J. R. (1980). Pattern of interaction in children's friendships. In H. C. Foot, A. J. Chapman \& J. R. Smith (Eds), Friendship and Social Relations in Children. New York: Wiley.

Grube, J. W., Morgan, M. 8c Kearney, K. A. (1989). Using self-generated codes to match questionnaires in panel studies of adolescent substance use. Additive Behaviors, 14, 159-171. 
Grube, J. W., Morgan, M. Be. McGree, S. (1986). Attitudes and normative beliefs as predictors of smoking intentions and behaviours: A test of three models. British Journal of Social Psychology, 25, 81-94.

Hartup, W. W., Laursen, B., Stewart, M. I. \& Eastenson, A. (1988). Conflict and friendship relations of young children. Child Development, 5, 1590-1600.

Hays, R. B. (1984). The development and maintenance of friendship. Journal of Social and Personal Relationships, 1, 75-98.

Hays, R. B. (1985). A longitudinal study of friendship development. Journal of Personality and Social Psychology, 48, 909-924.

Hays, R. B. (1989). The day-to-day functioning of close versus casual friendships. Journal of Social and Personal Relationships, 6, 21-37.

Huston, T. L. \& Levtnger, G. (1978). Interpersonal attraction and relationships. Annual Review of Psychology, 29, 115-156.

Johnson, M. R. D., Bewley, B. R., Banks, M. H., Bland, J. M. \& Clyde, D. V. (1985). Schools and smoking: School features and variations in cigarette smoking by children and teachers. British Journal of Educational Psychology, 55, 34 - 44 .

Kandel, D. B. (1980). Drug and drinking behaviour among youth. Annual Review of Sociology, 6, 235-285.

Kandel, D. B. (1985). On processes of peer influence in adolescent drug use: A developmental perspective. Advances in Alcohol and Substance Abuse, 4, 139163-

Kaplan, H. B., Martin, S. S. 8c Robbins, C. (1984). Pathways to adolescent drug use: Self-derogation, peer influence, weakening of social controls and early substance use. Journal of Health and Social Behaviour, 25, 270-289.

Kearney, K. A., Hopkins, R. H., Mauss, A. L. \& Weisheit, R. A. (1984). Self-generaced identification codes for anonymous collection of longitudinal questionnaire data. Public Opinion Quarterly, 48, 370-378.

Krosnick.J. A. \&Judd, C. M. (1982). Transitions in social influence in adolescence: Who induces smoking? Developmental Psychology, 18, 359-368.

McGuirc, K. D. \& Weisz, J. R. (1982). Social cognition and behavior correlates of preadolescent chumship. Child Development, 53, 1478-1484.

Morgan, M. \& Grube, J. W. (1989). Adolescent cigarette smoking: A developmental analysis of influences. British Journal of Developmental Psychology, 7, 179-189.

Newcomb, A. F., Brady, J. E. \& Hartup, W. W. (1979). Friendship and incentive conditions as determinants of children's task-oriented social behaviour. Child Development, 50, 878-881.

Newcomb, M. D., Huba, G. J. $8 c$ Bentler, P. M. (1983). Mothers' influence on the drug use of their children: Confirmatory tests of direct modelling and mediational theories. Developmental Psychology, 19, 714-726.

Parker, J. P. \& Asher, S. R. (1987). Peer relations and later personal adjustment: Are low-accepted children at risk? Psychological Bulletin, 102, 357-389.

Pedhazur, E. (1982). Multiple Regression in Behavioural Research. New York: Holt, Rinehart \& Winston.

Ritter, C. (1988). Resources, behavior intentions, and drug use: A ten-year national panel analysis. Social Psychology Quarterly, 51, 250-264. 